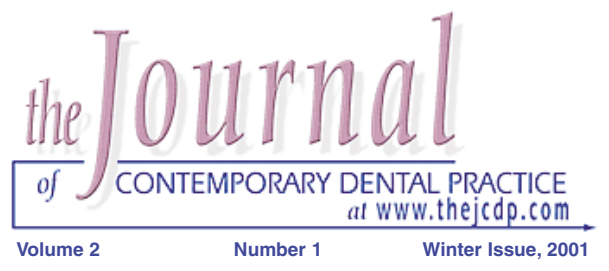

\title{
Effects of a Chewable Sodium Bicarbonate Oral Composition of Plaque and Gingivitis
}
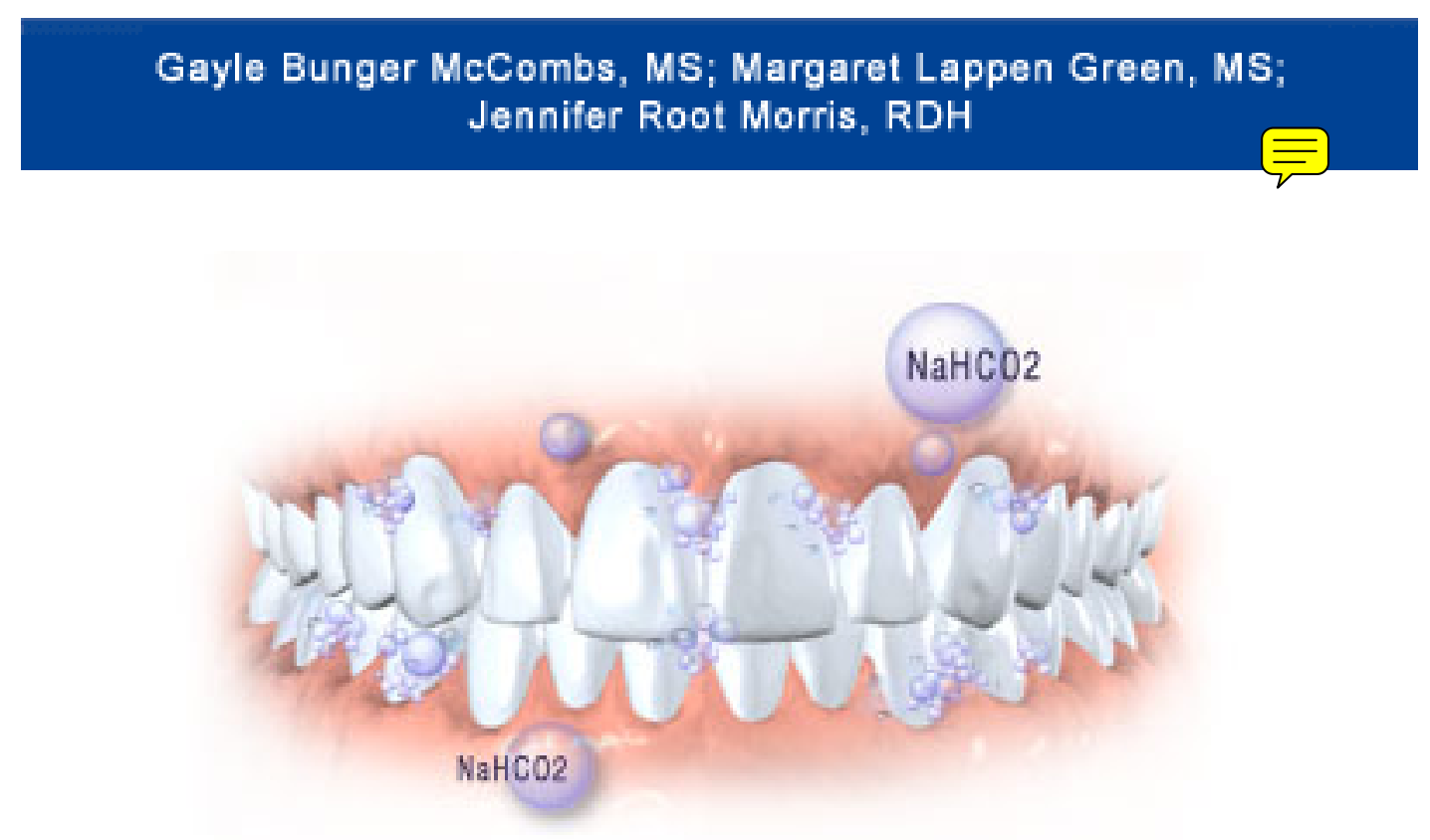

\begin{abstract}
The purpose of this pilot study was to evaluate the ef fects of an effervescent sodium bicarbonate based oral composition on plaque and gingivitis. Subjects selected for this study presented at screening with moderate plaque and American Academy of Periodontology (AAP) Type I/II periodontal status. At baseline, subjects were allocated to one of two groups by simple randomization; placebo $(n=16)$ and active $(n=16)$. During the study two subjects withdrew due to non-compliance and one because of a death in the family. Data were collected at baseline, day 14, and day 28. The Plaque Index (PI) of Silness and Loe was used to quantify the amount of supragingival plaque surrounding six selected teeth $(3,14,8$, 19, 24, 30), and the Gingival Index (Gl) of Loe and Silness was used to assess bleeding tendencies and visual appearance on the same six teeth. A soft tissue oral assessment was completed at each visit. Subjects were asked to perform study treatment three times a day, after meals, and continue with normal oral hygiene procedures. Subjects were requested to complete a 28-day diary to assess compliance. Data were analyzed using repeated measures analysis of variance. There were no statistically significant differences between the placebo and the active product groups and no statistical significant interaction between product and location within the mouth or visit for either the plaque or gingival scores. Results reveal the product was safe to oral tissues and was well accepted by subjects.
\end{abstract}

Keywords: Sodium bicarbonate, plaque, gingivitis, mouthrinse

(C) Seer Publishing

The Journal of Contemporary Dental Practice, Volume 2, No. 1, Winter Issue, 2001 


\section{Introduction}

The purpose of this study was to evaluate the ef ficacy of a new, over-the-counter, effervescent sodium bicarbonate based oral composition on plaque and gingivitis. The oral care product is supplied in a tablet form which when chewed mixes with the saliva to become a rinse which may be swallowed or expelled. This product is being marketed for the consumer "on the go" as a means of reducing plaque when brushing is not possible. (Figure 1) This experimental rinse in chewable tablet form contains a base of sodium bicarbonate in addition to citric acid, sorbitol, binders, menthol, and mint flavorings.

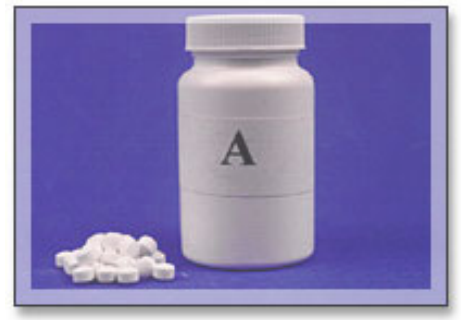

Few dental professionals have the time, nor the inclination, to conduct research on products supported by advertiser's claims; so they

rely on product evaluation by unbiased agencies and on products approved by the American Dental Association (ADA). Product evaluation has become an important part of the dental profession due to the influx of products available. Today, the practicing dentist or dental hygienist faces an enormous task in attempting to evaluate all the dental healthcare products available and to sort out the ones that are considered cosmetic or provide transitory effects. ${ }^{1,2}$

In addition to the over-the-counter products market, there are hundreds of products available at professional meetings and through Internet pharmacies. It is not humanly possible to spend the time necessary to obtain sufficient information on manufacturer's claims in order to make a critical judgment about whether something is safe and effective. The over-the-counter market is a billion-dollar industry flooded with products, which claim to have all sorts of benefits.

Aside from toothpaste and manual toothbrushes, mouthrinses represents about $23 \%$ of public spending on various oral hygiene products and over $50 \%$ of the public use a mouthrinse once or more daily. ${ }^{3}$ The effort to gain a share in the mouthrinse marketplace is tremendous. As professionals we want to see new products being developed, but at the same time we need to make evidence-based decisions and recommendations to our clients.

The current understanding of gingivitis is defined as marginal inflammation of the gingiva in direct response to bacterial accumulation on the teeth known as dental plaque. ${ }^{4} \quad$ Bacterial plaque is generally considered to be the main etiological agent in gingivitis and periodontal disease.

Generally, inflammation of the gingiva is in direct response to bacterial accumulation and maturation in otherwise healthy individu als. Since plaque-associated gingivitis is initiated by the accumulation of bacterial plaque adjacent to the gingival tissues, supragingival plaque control is essential for maintenance of oral health.

Gingivitis is commonly associated with poor oral hygiene and its capacity to progress to periodontitis. Most patients are aware of the necessity of brushing and flossing on a daily basis, but in spite of much research in the areas of dental health education and patient compliance/motivation, client self-care still remains a frustrating issue.

Researchers suggest the adjunctive use of overthe-counter products is a reasonable strategy for patients who are unable or unwilling to achieve acceptable levels of mechanical plaque control and gingival health. ${ }^{4}$

Although most adults practice some form of oral hygiene, this practice has not been successful for all individuals in maintaining optimal gingival health. Dental professionals need to explore all options available that would serve to motivate individuals to perform the moderately demanding daily oral hygiene regime necessary to maintain good oral health.

Mouthrinses have been used for many centuries for medicinal and cosmetic purposes, but in recent years the scientific community has put these products to the test through scientific 
research and clinical trials. Numerous antiplaque and anti-gingivitis studies have been reviewed with first and second-generation mouthrinses in the search for an effective chemical plaque-control agent that would provide a practical approach toward expanding the benefits of routine oral hygiene procedures. ${ }^{5-11}$ Most dental professionals agree the first attempt of controlling plaque should be through mechanical means, but many support the use of mouthrinses as an adjunct to oral care.

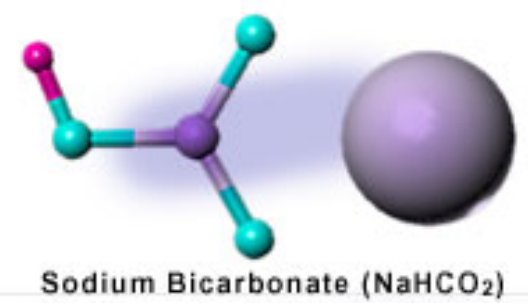

Sodium bicarbonate $\left(\mathrm{NaHCO}_{2}\right.$, baking soda) and salt, separately or in combination, have been widely used as a dentifrice, their use preceding the introduction of modern toothpaste. ${ }^{12}$ The appeal of sodium bicarbonate products seems to lie in its safety, low cost, low abrasivity, water solubility, buffering ability, compatibility with fluoride, and, in high concentrations, antibacterial properties. $^{13,14}$ Over the years, antimicrobial agents, such as sodium bicarbonate, have been incorporated into mouthrinses and dentifrices in an attempt at providing a practical approach toward improving oral health. Despite data presented in the American Academy of Periodontology's (AAP) Position Paper ${ }^{15}$ on understanding the role baking soda and hydrogen peroxide play in the treatment of periodontal disease, the market for peroxide-baking soda products indicates the public perception of a benefit for this combination. ${ }^{12}$ Though the product tested in this study does not contain peroxide, it does represent the response to the consumer's desire for baking soda products that are safe and natural.

\section{Materials and Methods}

Participants were recruited from the Hampton Roads area in Norfolk, Virginia. Qualifying subjects were between 18 and 55 years of age, no oral prophylaxis for at least 30 days, moderate plaque levels, and in general good health.

Participants were excluded if they:

1. had high blood pressure;

2. were on a salt restricted diet;

3. were pregnant;

4. presented with less than 18 teeth;

5. exhibited AAP Type III or greater periodontal disease;

6. exhibited gross oral neglect.

Prior to any treatment, each subject completed a health history and signed a consent form approved by Old Dominion University Institutional Review Board. Subjects were invited to participate in the study if they presented with an acceptable medical history and met all other inclusion criteria. At screening, a visual evaluation was conducted using a $0.2 \%$ erythrosine disclosing agent to calculate plaque levels. Thirty-two participants who met the inclusion criteria were randomly allocated to either active (tablet) or control (liquid) group using simple randomization. During the study, 2 subjects withdrew due to personal responsibilities and 1 because of a death in the family; placebo $(n=15)$ and active $(n=14)$.

Data assessments were obtained at baseline and on two follow-up visits (day 14 and day 28) for gingival bleeding, changes in normal gingival color, and supragingival plaque accumulation. At baseline, a full mouth circumferential periodontal probing was completed to determine periodontal status. Before each observation, the subject's medical history was reviewed and an oral soft tissue examination was conducted. A trained, calibrated dental hygienist with over 30 years clinical experience was the single examiner.

Table 1. Subject Demographics

\begin{tabular}{|l|l|l|l|l|}
\hline & White & African American & Asian & Other \\
\hline Male & 5 & 4 & 1 & 2 \\
\hline Female & 10 & 6 & 0 & 1 \\
\hline Total & 15 & 10 & 1 & 3 \\
\hline
\end{tabular}




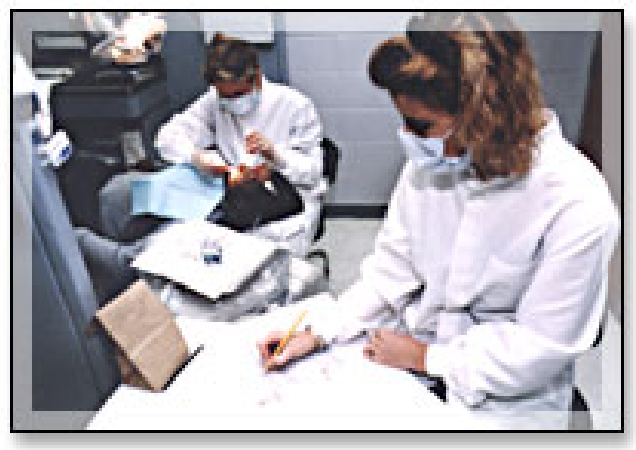

At the beginning of each treatment appointment, gingivitis was measured using the Gingival Index (GI) of Loe and Silness ${ }^{16}$ to assess the severity of gingival tissues adjacent to selected teeth numbers $3,8,14,19,24$, and 30 at distal, facial, mesial, and lingual sites. A score from 0-3 was assigned for each tooth using the following criteria:

- Absence of inflammation.

- Presence of mild inflammation, slight change in color, slight edema, and no bleeding on probing.

- Presence of moderate inflammation, moderate redness and edema with bleeding on probing.

- Presence of severe inflammation, marked redness and edema, and tendency toward spontaneous bleeding.

The Plaque Index (PI) of Silness and Loe ${ }^{17}$ was used to quantify supragingival plaque accumulation. Plaque scores were recorded from the same six selected teeth at the same sites. Three drops of an erythrosine disclosing agent were placed into a paper cup and gently dispersed on the teeth with a cotton tip applicator. Subjects then rinsed and expelled. A score from 0-3 was assigned for each tooth using the following criteria:

- No plaque present.

- Presence of a film of plaque adhering to the gingival margin and adjacent area of the tooth.

- Presence of moderate accumulations of plaque within the gingival sulcus that can be seen with the naked eye, or on the tooth and gingival margin.

- Presence of an abundance of plaque within the gingival sulcus and/or on the tooth and gingival margin.
At baseline a daily diary and a 14-day supply of study product was dispensed. Each subject was isolated and provided with appropriate oral and written instructions for product use by the research assistant. Then, under supervision, subjects performed the assigned treatment procedure using either the liquid or tablet. A liquid containing essentially the same composition as the tablet with the exclusion of the sodium bicarbonate was used as the placebo rinse.

During the experiment, subjects were instructed to continue their regular non-supervised, self-performed plaque control measures with the addition of chewing 3 tablets or swishing with one ounce of liquid, three times per day, after meals, for 28 days. Subjects who received the tablets were advised the product would effervesce as it mixes with the saliva and they may swallow or expel after the foaming action ceased. Subjects assigned to the tablet group were advised to chew the tablets, swish the mixture for $30 \mathrm{sec}-$ onds, then swallow or expel. Subjects assigned to the liquid group were advised to swish the liquid for the same amount of time and then swallow or expectorate. Subjects were unaware of which product was active. The examiner was masked to

product composition and allocation.

During the study subjects were asked to complete a 28-day diary to assess product compliance, record treatment times, any deviations from protocol, concurrent medications, and to elicit any additional comments. The 14-day diary was distributed at baseline, along with oral and written instructions for completing forms. At week two, an additional 14-day diary was distributed along with another two-week supply of study treatment. At the end of each treatment sequence, the diary and remaining study product was collected. 
Results

The primary outcome measure of this study was to assess the difference in plaque accumulations between product and placebo. A secondary outcome measurement was the difference in gingival assessment between product and placebo groups.
Results suggest there were no statistically significant differences for either plaque or gingival scores between group composition by location within the mouth for three time points. A three-way analysis of variance with repeated measures yields a p-value of .339 and .808 respectively. (Table 2 and Table 3 )

Table 2

\begin{tabular}{|l|l|l|l|l|}
\hline Composition & Location & Time & Mean & Std \\
\hline Placebo & Anterior & T1 & 1.175 & 0.154 \\
\hline & & T2 & 1.533 & 0.132 \\
\hline & & T3 & 1.292 & 0.141 \\
\hline
\end{tabular}

\begin{tabular}{|l|l|l|l|l|}
\hline Placebo & Posterior & T1 & 1.363 & 0.123 \\
\hline & & T2 & 1.467 & 0.122 \\
\hline & & T3 & 1.104 & 0.127 \\
\hline
\end{tabular}

\begin{tabular}{|l|l|l|l|l|}
\hline Active & Anterior & T1 & 1.402 & 0.16 \\
\hline & & T2 & 1.402 & 0.136 \\
\hline & & T3 & 1.455 & 0.146 \\
\hline
\end{tabular}

\begin{tabular}{|l|l|l|l|l|}
\hline Active & Posterior & T1 & 1.156 & 0.128 \\
\hline & & T2 & 1.263 & 0.127 \\
\hline & & T3 & 1.103 & 0.131 \\
\hline
\end{tabular}

Note: $\mathrm{p}$ value $=0.339 ; \mathrm{T} 1=$ baseline; $\mathrm{T} 2=$ day $14 ; \mathrm{T} 3=$ day 28

Table 3

\begin{tabular}{|l|l|l|l|l|}
\hline Composition & Location & Time & Mean & Std \\
\hline Placebo & Anterior & T1 & 0.6 & 0.146 \\
\hline & & T2 & 0.508 & 0.142 \\
\hline & & T3 & 0.542 & 0.116 \\
\hline
\end{tabular}

\begin{tabular}{|l|l|l|l|l|}
\hline Placebo & Posterior & T1 & 0.617 & 0.108 \\
\hline & & T2 & 0.821 & 0.101 \\
\hline & & T3 & 0.775 & 0.096 \\
\hline
\end{tabular}

\begin{tabular}{|l|l|l|l|l|}
\hline Active & Anterior & T1 & 0.384 & 0.152 \\
\hline & & T2 & 0.545 & 0.147 \\
\hline & & T3 & 0.411 & 0.12 \\
\hline
\end{tabular}

\begin{tabular}{|l|l|l|l|l|}
\hline Active & Posterior & T1 & 0.42 & 0.112 \\
\hline & & T2 & 0.688 & 0.104 \\
\hline & & T3 & 0.634 & 0.099 \\
\hline
\end{tabular}

Note: $\mathrm{p}$ value $=0.808 ; \mathrm{T} 1=$ baseline; $\mathrm{T} 2=$ day $14 ; \mathrm{T} 3=$ day 28 
Data also suggests there were no statistically significant differences among group and time within the mouth for either plaque or gingival scores. A two-way analysis of variance yielded a $p$-value of .810 and .511 respectively. (Figure 2 and Figure 3) Alpha was set at 0.05 .

With regard to both plaque and gingival health there was no statistically significant difference between product and placebo, and there was no statistically significant interaction between treatment and location within the mouth. Clinical evaluation of the oral mucosa suggests the product is safe to oral tissues. One subject from the product group reported a burning sensation on the tongue, and two subjects reported tissue sloughing which lasted from 1-2 days. One subject on placebo reported gingival irritation on day seven. These adverse experiences, although annoying, resolved and did not interfere in any significant manner with the patient's normal functioning level. Of the 27 participants who completed the exit interview, $74 \%$ of them said they would purchase the product as an over-the-counter oral healthcare supplement if it was found to be effective.

\section{Discussion}

As consumers become more aware of over-thecounter oral care products, the demand will increase for safe, easy to use, mild, but ef fective products to supplement traditional oral hygiene care increases. This trend places a burden on

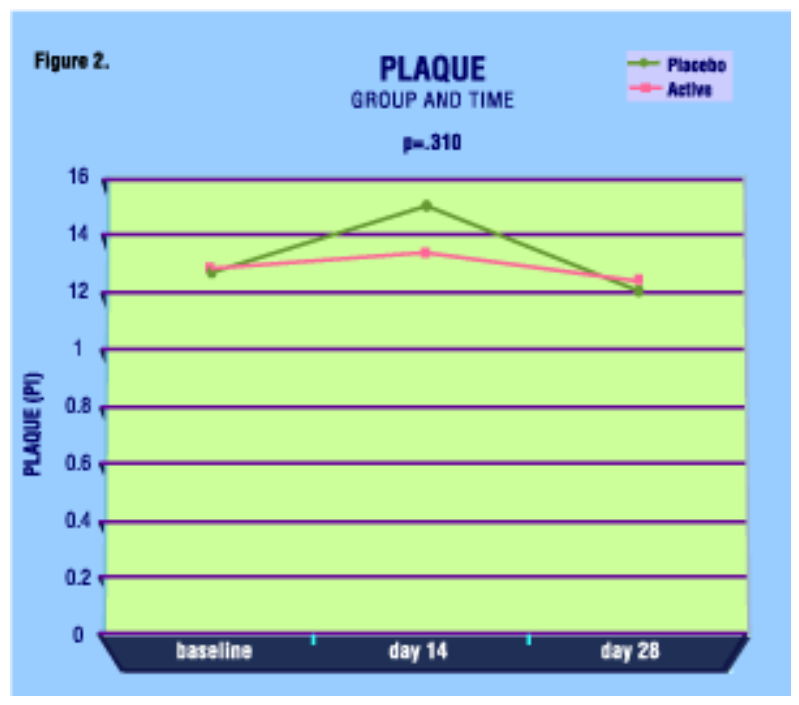

the dental professional to remain current with the ever-increasing number of products available to the consumer.

The search for an effective plaque reducing agent has a checkered past, but researchers agree the value of such an agent is obvious. The impact of an adjunctive plaque control agent that is safe, efficacious, inexpensive, easy to use, and available over-the-counter would appeal to those who fail to achieve effective oral self-care or have impaired physical dexterity. The new sodium bicarbonate tablet/rinse evaluated in this study does not propose to be a substitute for conventional periodontal therapy, but was evaluated on its effectiveness as an adjunct to routine oral hygiene procedures.

\section{Conclusion}

Longer-term, large-scale studies need to be conducted to investigate the possible mechanisms of action of this sodium bicarbonate oral composition on plaque and gingivitis. The use of the Turesky PI and the addition of microbial data should be considered. Despite the limitations of this study, it does represent the need to evaluate the increasing number of products appearing on the over-the-counter market shelves. Dental professionals must be prepared to make evidencebased decisions to address advertiser's claims of product effectiveness and assist clients in making choices about over-the-counter products.

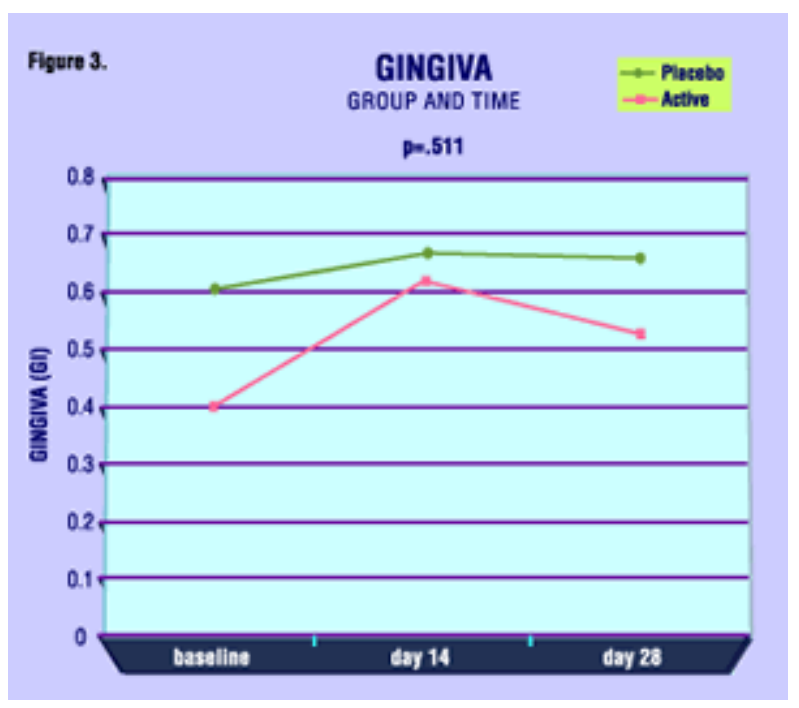




\section{References}

1. Phillips M. Product evaluations: a general practitioner's perspective. J Clin Dent 1995;6: 174-175.

2. Mandel I. The mouthrinse wars. J Periodontol 1989;60: 478-480.

3. Bakdash B. Current patterns of oral hygiene product use and practices. Periodontology 2000 1995;8: 11-14.

4. Van Dyke TE, Offenbacher S, Philstrom B, et al. What is gingivitis? Current understanding of Prevention, treatment, measurement, pathogenesis and relation to periodontitis. J Intl Acad Periodontol 1998;1(1): 000-000.

5. Adams D, Addy M. Mouthrinses. Adv Dent Res 1994;8: 291-301.

6. Ciancio S. Expanded and future uses of mouthrinses. J Am Dent Assoc 1994;125 Suppl 2: 29S$32 S$.

7. Mandel ID. Antimicrobial mouthrinses: overview and update. J Am Dent Assoc 1994;125 Suppl 2: 2S-10S.

8. Bacca LA, Leusch M, Lanzalaco AC, et al. A comparison of intraoral antimicrobial effects of stabilized stannous fluoride dentifrice, baking soda/peroxide dentifrice, conventional $\mathrm{NaF}$ dentifrice and essential oil mouthrinse. J Clin Dent 1997;8: 54-61.

9. Nelson RF, Rodasti PC, Tichnor A, et al. Comparative study of four over-the-counter mouthrinses claiming antiplaque and/or antigingivitis benefits. Clin Prev Dent 1991;13(6): 30-33.

10. Fine DH. Mouthrinses as adjuncts for plaque and gingivitis management. A status report for the American Journal of Dentistry. Am J Dent 1988;1: 259-263.

11. Axelsson $P$ and Lindhe $J$. Efficacy of mouthrinses in inhibiting dental plaque and gingivitis in man. $J$ Clin Periodontol 1987;14: 205-212.

12. Fischman SL. The history of oral hygiene products: how far have we come in 6000 years? Periodontol 2000 1997;15: 7-14.

13. Newburn $\mathrm{E}$. The use of sodium bicarbonate in oral hygiene products and practice. Compendium Contin Educ Dent (Supplement) 1997;21: S2-S7.

14. Drake D. Antibacterial activity of sodium bicarbonate. Compendium Contin Educ Dent (Supplement) 1997;21: S17-S21.

15. Current understanding of the role of microscopic monitoring, baking soda, and hydrogen peroxide in the treatment of periodontal disease. Committee on Research, Science and Therapy. The American Academy of Periodontology, J Periodontol 1998;69: 951-954.

16. Loe H. The Gingival Index, the Plaque Index and the Retention Index Systems. J Periodontol 1967;38: 610-616.

17. Silness J, Loe H. Periodontal disease in pregnancy. II. Correlation between oral hygiene and periodontal conditions. Acta Odontol Scand 1964;22(1): 121-135. 


\section{Gayle Bunger McCombs, RDH, MS}

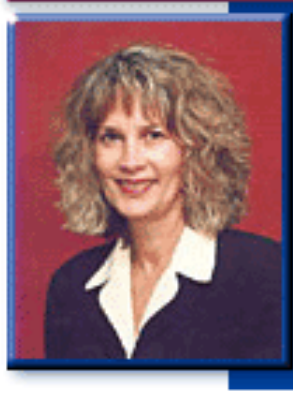

Gayle McCombs is an Assistant Professor and Director of the Dental Hygiene

Research Center at Old Dominion University. She received her Associate's degree in dental hygiene from Florida Community College; her Bachelor of Science degree from the University of West Florida and her Masters of Science degree from the University of North Carolina at Chapel Hill. In addition to her undergraduate and graduate teaching responsibilities, her primary interests are in conducting clinical trials for testing new dental products and devices.

e-mail: Gmccombs@odu.edu

\section{Margaret Lappen Green, RDH, MS}

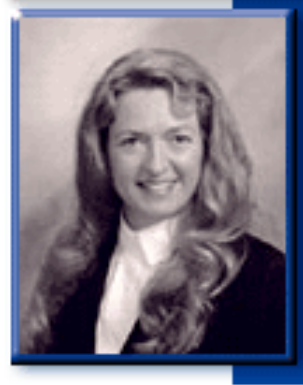

Margaret Green received her dental hygiene degree from the University of Pittsburgh, School of Dental Medicine and is a graduate of California State and Columbia Universities. She is an Adjunct Professor at OId Dominion University and a private practitioner. Margaret is a former Vice President of ADHA, a member of the Virginia Board of Dentistry and is actively involved as a research hygienist.

e-mail: Bmgreen@erols.com

\section{Jennifer Root Morris, RDH}
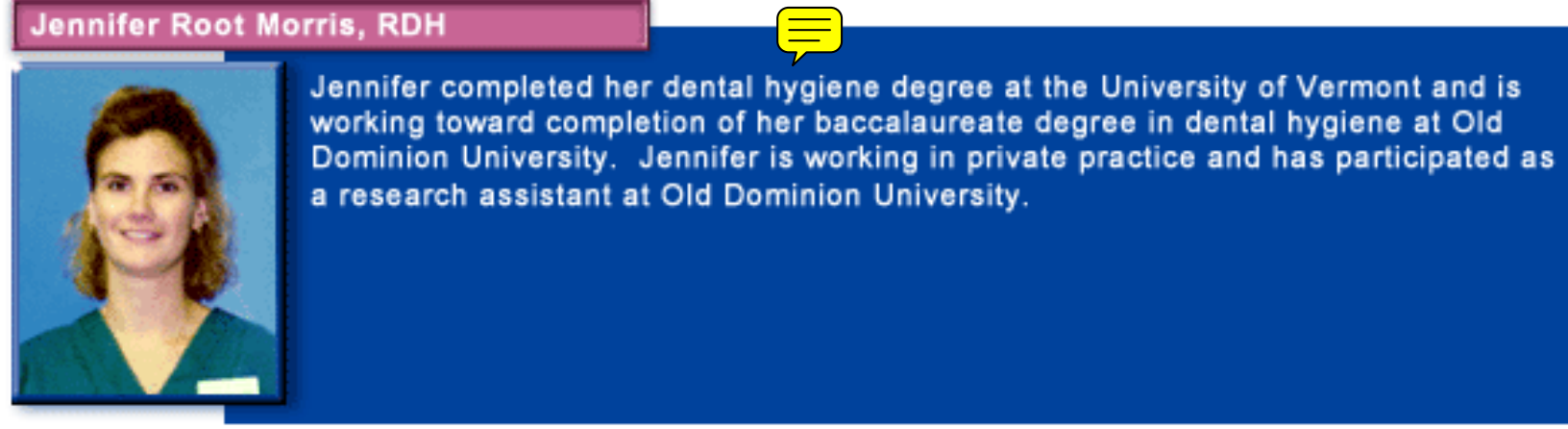

Support received from Ellis Health Laboratories, Chino, California.

Contact person: Gayle McCombs

Old Dominion University

School of Dental Hygiene Norfolk, VA 23529

757-683-5150

\section{Acknowledgements}

The authors wish to express their appreciation to Dr. Ceib Philips and Dr. Paul Stepanovich for providing statistical support. 